\title{
LA NUEVA CARA DE LA HISTORIA ECONOMICA DE ESPAÑA (I)
}

FRANCISCO BUSTELO

Universidad Complutense

El propósito de estas líneas es hacer una reseña, o más bien dar noticia, de tres publicaciones que han visto la luz recientemente y que suponen una aportación notable a la historia económica de los siglos xIx y xx.

Se trata, por orden de aparición y, a mi juicio, también por orden de importancia, del número 20 de Papeles de Economía Española, la excelente revista de la Confederación Española de Cajas de Ahorro (Fundación Fondo para la Investigación Económica y Social), que está dedicado a $*$ La nueva cara de la historia económica de España»; de un libro compilado por Nicolás SánchezAlbornoz y que con el título La modernización económica de España 1830 . 1930 ha editado Alianza Universidad (reúne las exposiciones presentadas en un seminario que sobre ese tema se celebró en la Universidad Internacional, en Santander, en agosto de 1983); y del número 623 de Información Comercial Española, la veterana revista del Ministerio de Economía y Hacienda, y que es casi monográfico sobre el "Fracaso de la Revolución Industrial" (recoge ponencias presentadas en un seminario que sobre el libro de Nadal que lleva ese título celebró el Centro Ortega y Gasset, de Madrid, en la primavera de 1985). Aunque cada una justificaría con creces un comentario por separado, aquí se engloban las tres publicaciones por la unidad que ofrece su contenido.

De los 45 artículos que figuran en ellas, la historia económica del siglo XIX es la que se lleva la parte del león, con 27 trabajos. Además, de los 14 artículos sobre temas regionales, salvo uno que trata del Madrid de los siglos xín y xVIII, todos los demás se refieren al siglo xIX, casi siempre juntamente con la primera parte del siglo xx. Sobre esta última centuria hay cuatro trabajos específicos, y cierran la lista dos colaboraciones sobre teoría de la historia económica y dos sobre Latinoamérica, las cuatro en Papeles. También en esta revista, como capítulo aparte, figuran las semblanzas de tres maestros de la historia económica (Carande, García de Valdeavellano y Vicens Vives) y un atractivo apartado sobre «Corrientes actuales de investigación», con opiniones de seis ilustres profesores. 
El comentario a todos esos trabajos se ha dividido, por razones de espacio, en dos partes. La primera, que ve la luz hoy, se ocupa de los 27 artículos sectoriales o globales sobre el siglo XIX y los dos relativos a América Latina. (Su relación puede verse al final de estas notas.) La segunda, que se publicará en el próximo número de la $R H E$, reseñará los demás.

Insisto en que la elevada calidad de este material aconsejaría referencias más pormenorizadas de lo que aquí hago, donde por querer ofrecer un panorama general me limitaré a un análisis somero por grandes capítulos temáticos, indicando lo que reviste mayor interés para saber cuál es el «estado de la cuestión», por así decirlo, de la historia económica de las épocas estudiadas, tal como se desprende de este valioso conjunto de investigaciones.

\section{Agricultura}

Los seis trabajos dedicados a este tema se desglosan en una visión muy general del sector agrícola en la España moderna por Gonzalo Anes, dos artículos de Tortella sobre el período 1890-1930 (en realidad, uno es ampliación del otro) y sendos trabajos sobre desamortización de Simón Segura, Rueda y Donézar.

En la agricultura española se ponen muy de manifiesto los problemas, muchos todavía sin resolver, que suscita el subdesarrollo decimonónico en nuestro país. En Papeles ( «La agricultura de la economía de la España contemporánea: 1830-1930»), Tortella explica sucintamente y con claridad los requisitos que ha de cumplir una agricultura para impulsar la revolución industrial (en este y otros trabajos se echan de menos, sin embargo, más referencias a la teoría económica agraria; por ejemplo, a los trabajos de Theodore Schultz, el Premio Nobel de Economía, que ha escrito páginas muy interesantes para el historiador sobre agricultura tradicional y agricultura moderna) y cómo el sector primario español no contribuyó, o lo hizo en escasa medida, al desarrollo de la economía hispana. Además, en su colaboración al libro sobre La modernización («Producción y productividad agraria, 1830-1930»), Tortella añade un muy interesante epígrafe sobre los problemas con que se tropieza para estimar la producción agraria del siglo xIX, verdadero escollo que nos impide tener una visión más cabal de la historia agraria de la época y, por ende, de todo el fallido proceso de industrialización. Entre los aspectos que por su interés llaman la atención figura el consumo de trigo por habitante y año, que a mediados del xIX sería de algo menos de $90 \mathrm{Kg}$., de 144 en 1891-1900 y de más de 170 en 1901-1910, para luego disminuir otra vez (hoy es inferior a 100). Los cereales en general resultan ser así un bien superior, con elasticidad demanda-renta mayor que uno, en situaciones de subdesarrollo o predesa- 
rrollo, para luego, a partir de cierto nivel, considerarse un bien inferior, con elasticidad negativa. (En España, el trigo ha pasado de suponer, hasta hace treinta años, el 40 por 100 de la dieta al 15 ó 20 por 100 actual, con una evolución que se ajusta sorprendentemente bien a la que registran todos los países estudiados por la FAO, en El estado mundial de la agricultura y la alimentación, 1954.)

En el artículo de Tortella de Papeles hay un encuadre de dos páginas del Grupo de Estudios de Historia Rural sobre el uso del suelo y la producción agraria en España en 1891-1931, donde se demuestra con los datos actualmente conocidos, y sin duda susceptibles de perfeccionamiento, que hubo progresos sustanciales en la productividad del factor tierra ( 58 por 100 de mejora en ese período) y del trabajo (en porcentaje que no se indica y que sería probablemente algo menor). De la rentabilidad del capital, nada sabemos.

Gonzalo Anes ( $\mathrm{El}$ sector agrario en la España moderna», Papeles), con sus muchos conocimientos sobre los siglos XVI a xviII y su capacidad de síntesis y exposición, pasa revista al sector agrario de la España moderna, cuando todavía la agricultura prácticamente no registraba cambios, al igual de lo que sucedía «en cualquier otro país del mundo». Entre las contadas modificaciones, señala Anes, con un curioso análisis costo-beneficio, la sustitución de bueyes por mulas, las variaçiones en las complejas relaciones entre agricultura, ganadería y bosque, la introducción del maíz y poco más. Este autor, como es sabido, se basa para su modelo general, obviamente «antiboserupiano», de la agricultura y la economía del Antiguo Régimen en los cambios de la población -considerada como variable independiente- para explicar los altibajos seculares de la producción agrícola, dentro de un marco casi invariable. Los incrementos de la oferta para responder a una mayor demanda, derivada del mayor número de bocas que alimentar, se lograban por una extensión de las tierras cultivadas, en el siglo xvi rompiendo pastos y en el xviII haciendo probablemente lo mismo, además de rozar monte bajo, con las consiguientes dificultades que aquello suscitaba en las relaciones con la Mesta.

Conclusiones importantes son la ausencia de elementos que expliquen por sus raíces históricas el retraso relativo del sector agrario en el siglo XIX. Tanto más cuanto que ya en el siglo xviri empiezan los cambios jurídicos que resultan obligados para poder desarrollar las fuerzas productivas. Aunque no hubiera, claro está, un cambio radical como el que acarreara la Revolución Francesa en el país vecino, sí que iban sentándose las bases para posibles modificaciones ulteriores de mayor enjundia. El que éstas no se materializaran plenamente, ¿cómo podría explicarse?

Lo que sí parece evidente, en la desamortización, por ejemplo, es que más tranquilidad, menos agobios fiscales y cierta perspectiva (ya que en agricultu$\mathrm{ra}$, tal vez más que en otros sectores, hay que actuar a medio plazo) hubieran 
arrojado mejores resultados. Porque en España no hubo revolución en la agricultura, pero sí intentos continuados de modificar aspectos esenciales de la tenencia de la tierra. La desamortización, con sus muchas dimensiones - jurídica, social, económica, fiscal, municipal y religiosa-, es el hecho más importante, o al menos el más visible, de lo que sucedió en el sector primario. Gracias a los trabajos de Simón Segura, iniciados hace ya tiempo («La desamortización española en el siglo xIX», Papeles), y de otros más recientes, entre los que se cuentan los de Rueda ( «La desamortización de Mendizábal y Espartero», ICE) y Donézar ( «Los bienes de los pueblos y la desamortización», $I C E$ ), que figuran en las publicaciones que comentamos, se conoce mejor ese proceso tan dilatado, a veces confuso, crucial sin duda, y que, sin embargo, no propició el paso a una agricultura moderna. Los problemas que suscita son muchos y no cabe aquí ni siquiera enumerarlos. Con todo, hay que señalar que trabajos como los señalados parecen confirmar que el grado de concentración de la propiedad de la tierra se agravó con el proceso desamortizador «en proporción al grado ya existente», en palabras de Rueda (que sigue así a Richard Herr), y que braceros y vecinos pobres de los pueblos, éstos al perderse los bienes de propios y los comunes, vieron empeorar su situación. Las salvaguardias, mejores o peores, que brindaba la organización socioeconómica del Antiguo Régimen desaparecieron, sin ser sustituidas por una agricultura moderna y capitalista que coadyuvase a una industrialización suministradora de empleos y agente eficaz para acabar elevando el nivel de vida de la población necesitada. (Aquí se halla, como es sabido, una de las claves para comprender la abigarrada historia política de la España contemporánea y el arraigo, por ejemplo, del carlismo o del anarquismo.)

Es discutible, sin embargo, lo que señala Donézar (en contra de una idea muy extendida de que la desamortización absorbió fondos que no se dedicaron a fines industriales) de que, en realidad, «las compras de tierras sirvieron para ayudar a la industrialización» vía el Estado. Este no aprovechó precisamente esos fondos, tampoco excesivos, para ayudar a la industria, sino más bien para taponar agujeros fiscales o, como mucho, para subvencionar los ferrocarriles, construidos y explotados en buena parte por extranjeros.

A Simón Segura me atrevería a pedirle que sortease un obstáculo que ofrece el análisis de la desamortización, cual es el de perderse en el estudio interminable de las compraventas y demás rasgos del proceso. Puesto que conoce bien el tema, sin perjuicio de seguir adentrándose en el necesario desbroce regional o monográfico, podría intentar un balance general acerca de qué fue, en suma, lo que cambió en la agricultura por causa de la desamortización, tras aquel tejemaneje de tierras y propietarios que durante decenios afectó a toda la geografía hispana.

De todos estos trabajos no se infiere, en definitiva, con claridad por qué 
no progresó más el campo español, ya que hubo intentos y estímulos. Es difícil decir que éstos fueran menores que en otros países, donde sí hubo cambio. Habría que descender a un plano microeconómico para estudiar, si cabe, lo que aconteció en las explotaciones desamortizadas y la razón de que en ellas no se alcanzara una nueva función de producción - la de la agricultura moderna- que mediante una mejor combinación de los medios productivos acreciese el excedente. Si se modificó positivamente la organización social, económica y jurídica y se incentivó el beneficio mediante una mayor demanda, ¿por qué no avanzó más la agricultura en el siglo XIX? ¿Cuestión de mentalidad? ¿Falta de economías externas? ¿Influencia negativa de otros sectores?

\section{Población}

Cinco son los trabajos consagrados a este capitulo. Nicolás Sánchez-Albornoz habla, en Papeles, de población y economía en Iberoamérica en los siglos xIx y xx; Vicente Pérez Moreda escribe nada menos que tres artículos, uno en cada una de las tres publicaciones reseñadas, sobre la población de los siglos $\mathrm{xIX}$ y $\mathrm{XX}$ (y los tres distintos, para mayor mérito), y, por último, yo mismo publico un trabajo sobre la demografía decimonónica en ICE.

El territorio de la actual América de habla española tenía cuando desembarcó Colón entre 15 y 60 millones de habitantes. Cuando la emancipación, a principios del siglo xix (es a partir de entonces de lo que habla SánchezAlbornoz en su trabajo), se contaban de 15 a 20 millones. En 1930 había un poco más de los 100 millones, y en 1980, 360 millones (para el año de gracia de 2025 se estiman 845 millones). Hay que reconocer que el simple enunciado de cifras tan dispares, con su explosión final, indica que el tema es a todas luces digno de estudio. Dejando de lado las convulsiones de la Independencia, con la consiguiente expulsión, entre otras cosas, de españoles, los países recién emancipados tenían en el siglo xIx un factor limitativo: la escasa mano de obra. De ahí la política inmigratoria que, con mejor o peor fortuna, siguieron todos ellos, al igual que lograron unos u otros resultados con su concatenación con los mercados internacionales, tras abandonar de buen grado el corsé que imponía la metrópoli. Mayor población significaba entonces mayor desarrollo, lo contrario de lo que sucede hoy. España, claro es, tuvo mucha relación con todo aquel proceso, salvo en las últimas etapas. Un latinoamericano o un español —en realidad, todo estudioso de la historia de la economía y de la población- ha de sentirse atraído por los elementos de reflexión que propone Nicolás Sánchez-Albornoz.

Vicente Pérez Moreda, en sus tres trabajos citados, confirma su talla, ya demostrada, de demógrafo histórico o historiador de la población, lo que, por cierto, según algunos, no sería lo mismo, cosa que cabe poner en duda. 
El arcaísmo demográfico de la España del xIx queda bien de manifiesto con la tardía transición demográfica, de la que sólo hay tímidos balbuceos en aquella centuria y que comienza, en realidad, ya iniciado el siglo $\mathbf{x x}$, con un lento desartollo y una culminación muy reciente. Trasunto fiel todo ello, huelga decirlo, del fracaso de la revolución industrial. No se produjo ésta y no hubo tampoco revolución demográfica. Todo siguió igual y hubo, sí, un crecimiento cuantitativo apreciable, sobre todo si se considera en la perspectiva de nuestra modesta historia de la población, aunque el aumento resulte irrisorio desde una óptica mundial. En cualquier caso, en 1900 prácticamente se nacía y se moría en España igual que en 1800, cuando en gran parte de Europa occidental y septentrional se había producido ya el salto radical que separa en natalidad y mortalidad, y con ello en esperanza de vida y distribución de la población por edades, las sociedades preindustriales de las avanzadas.

De estos artículos de Pérez Moreda, además de los muchos datos y de las comparaciones internacionales siempre convenientes (y en población imprescindibles), destacaría la información sobre movimientos migratorios -donde queda, sin embargo, mucho por hacer-y sobre las variables regionales del crecimiento demográfico. España fue en población, como en otros aspectos, un país plural, y aunque, lógicamente, Cataluña se pusiera a la cabeza en la transición, por su mayor desarrollo económico y tal vez por la influencia francesa en materia de control de nacimientos, hubo diferencias apreciables en las demás regiones y territorios. Tales diferencias se prestan a estudios, ya regionales, ya globales, sobre el diferente inicio del descenso de la mortalidad, por un lado, y de la baja de natalidad, por el otro.

Lo primero, si se conociera bien, permitiría averiguar la influencia relativa y cronológica de las dos causas que lo motivan, es decir, la mayor alimentación y la menor enfermedad, y la segunda plantea el problema, fundamental para el Tercer Mundo actual, de cuándo, cómo y por qué aparece el control de nacimientos.

Da datos, además, Pérez Moreda sobre dos variables fundamentales en demografía: la edad media de la mujer al contraer matrimonio (podríamos llamarla EMAM, a imitación del anglosajón SMAM, Single Mean Age at Marriage) y la proporción de célibes definitivos.

Sólo le pondría a este autor una pequeña "pega». Se trata de la tesis de que la población española creció más en la primera mitad del siglo xix que en la segunda (1800-1860 arrojaría, según Pérez Moreda, una tasa de crecimiento anual acumulativo de 0,59 por 100 , y $1860-1900$, de 0,43 por 100 ). Puesto que el período 1794 a 1815 fue de guerras y de crisis de subsistencias - que el propio Pérez Moreda ha estudiado en su excelente trabajo sobre las crisis de mortalidad-, tal cosa obliga a aceptar crecimientos muy grandes, casi im- 
posibles para la época, en $1815-1821(0,98$ por 100$)$ y $1815-1860(0,79$ por 100 ), ya que en $1794-1815$ hubo estancamiento o retroceso.

Esos altibajos tan grandes, difíciles de aceptar, desaparecen, en cambio, si se toma para 1800 una población de 11,5 millones en lugar de los 10,5 habituales, o incluso de los 11 por los que parece inclinarse Pérez Moreda. No sólo así la diferencia entre ambas mitades del siglo se reduce mucho, sino que la pequeña disminución del incremento demográfico desde 1860 se explicaría sólo por la emigración. Con los 316.000 emigrantes que Pérez Moreda encuentra para el período $1858-1900$, el crecimiento de $1860-1900$ es de 0,47 por 100 , casi igual al 0,51 por 100 que resulta en $1800-1860$, cuando se toma como número de habitantes en la primera de esas fechas los 11,5 millones indicados. Si investigaciones posteriores sobre la emigración, que, entre otros, está realizando el propio Pérez Moreda, arrojasen finalmente cifras superiores, lo que es perfectamente posible, resultaría que ambas mitades de siglo tuvieron igual crecimiento vegetativo de la población, lo que resultaría más lógico que lo contrario.

Por último, no me resisto a reproducir una cita que recoge nuestro autor de César Silió y Cortés, quien en su obra Los que nacen y los que mueren, publicada en Valladolid en 1897, hace una definición perfecta de lo que ocurre en población antes y después de la transición demográfica: «Francia es hoy en Europa el país de la esterilidad voluntaria, y España es en Europa el país de la mortalidad indisculpable. En la nación vecina, la población no crece apenas, porque nacen muy pocos. En la nuestra tampoco crece apenas, porque mueren muchos.»

Del breve trabajo que publico en ICE, me gustaría destacar el hecho de que las curvas de supervivencia de la población española de 1800, 1900 y 1975 muestran fehacientemente que en el siglo xix nada cambia en la demografía de nuestro país y que el gran salto cualitativo tiene lugar en el $\mathbf{x x}$, así como la necesidad de que en el estudio de la población se tengan en cuenta no sólo las variaciones cuantitativas, sino también el análisis cualitativo del comportamiento demográfico. Otra cosa induce a error, como lo hizo, y gravemente, en el caso del gran maestro de la historia económica Vicens Vives. Equivocación grande la suya al considerar que hubo en España en el siglo xIx una revolución demográfica que «hunde las estructuras hasta entonces vigentes y precipita los cambios económicos y políticos...». El que fuera otrora su discípulo, Jordi Nadal, corrigió adecuadamente tan injustificadas afirmaciones en $\mathrm{El}$ fracaso, en un capítulo, sin embargo, que al titularse «La población, ¿una falsa pista?" tiene un encabezamiento, como dice Pérez Moreda, poco afortunado, ya que la población, crezca o no crezca, registre muchos o pocos cambios cualitativos, siempre es una pista para saber qué es lo que sucede en la economía y en la sociedad. 


\section{Comercio exterior}

Como parte de sus investigaciones sobre el comercio exterior español desde 1715 a 1935 , Leandro Prados de la Escosura publica dos trabajos muy completos, uno en Papeles ( «La evolución del comercio exterior, 1790-1929») y otro en La modernización ( El comercio exterior y la economía española durante el siglo xix»), que ofrecen no sólo muchos datos sobre exportaciones e importaciones durante el siglo xIX y primer tercio del $\mathrm{xx}$, con constantes $\mathrm{y}$ encomiables comparaciones europeas e incluso mundiales, sino que, además, no olvidan en ningún momento el polémico asunto de las ventajas e inconvenientes que entrañaron las relaciones exteriores en la historia económica de nuestro país.

En teoría del desarrollo, como es sabido, la cuestión es importante y controvertida, pues frente a la obvia ampliación de mercados, mejor asignación de recursos y atracción de capitales que brindan las relaciones económicas y comerciales con otros países, se contraponen las relaciones de dependencia, los enclaves que muchas veces monta el capital extranjero en un país, los monocultivos o monoindustrias de exportación y el endeudamiento exterior, como elementos negativos.

España, como confirma Prados en sus dos trabajos, tuvo un comercio exterior que, en porcentaje de las exportaciones respecto de la renta nacional, supuso en el siglo xix unas proporciones que, sin llegar a las europeas en su conjunto, fueron, sin embargo, más que apreciables y tuvieron un peso grande en la economía española.

Además, como es sabido, la composición de ese comercio se modificó por causa de la pérdida de los mercados coloniales cautivos y de las propias variaciones de la demanda europea. Demostraron así los sectores de exportación bastante flexibilidad, y, además, tal como señala Prados, la relación real de intercambio fue favorable para España al menos hasta 1880, lo cual, claro es, lleva a preguntarse por qué el comercio exterior no surtió efectos más decisivos en el desarrollo económico español del siglo pasado.

Prados parece inclinarse, con Kravis, por la primacía de los factores internos, dejando a la demanda exterior un papel simplemente adicional. A mi juicio, esto resulta sólo a medias convincente, ya que en un plano económico más general no hay razones para trazar un corte radical entre demanda exterior y demanda interior $y$, por. lo tanto, para primar una sobre otra. Más lógico sería remitirse a la afirmación obvia de que en el desarrollo no hay nada esencial por sí solo, todo es «adicional», muchos cambios son necesarios pero no suficientes, y la revolución industrial se produce cuando en un espacio de tiempo relativamente corto confluyen muchos factores a la vez: demanda exterior, demanda interior, capitales nacionales y foráneos, cambios en la agri- 
cultura, revolución en los transportes, transición demográfica, mayor educación y algunas cosas más.

Para saber más del tema habrá que esperar a la publicación del gran trabajo que tiene Leandro Prados en curso de realización, y que, pese a estar todavía inédito, se autocita muchas veces como fuente. Cuando se publique, podrán aquilatarse mejor las fuentes de datos, ya que tener información fidedigna del comercio exterior no es fácil, por razones sabidas que no cabe repetir aquí. De lo que no hay duda es que se trata de un sector importante y sin él será imposible hacer un balance cabal del acontecer económico del siglo xIx.

\section{Ferrocarriles}

En este sector, tan polémico o más que el anterior, los muchos avances logrados, gracias a las aportaciones en los últimos años de Rafael Anes, Artola, Gómez Mendoza y Tedde, permiten completar y corregir las hipótesis lanzadas por los estudios - pioneros en esta y en otras materias- de Tortella y Nadal. En aquellos primeros trabajos a los ferrocarriles les correspondía, si no el papel de malo de la película, un «rol» que tampoco era el de galán, ya que, como es sabido, Tortella afirmaba que la construcción de los ferrocarriles, tal como se hizo, cerró la posibilidad de una política económica diferente y más positiva, con mayor hincapié en la industrialización propiamente dicha, mientras que para Nadal el sistema ferroviario, si hubiera sido distinto del que se construyó, habría impulsado mucho más la economía hispana.

Hoy, lo más convincente, a la luz de las investigaciones de los últimos diez años, figura en sendas afirmaciones que, como conclusión, cierran dos de los trabajos que aquí comentamos —el de Gómez Mendoza en Papeles ( Los efectos del ferrocarril sobre la economía española, 1855-1913») y el de Rafael Anes en ICE («El ferrocarril en la economía española»)-, y que vienen a decir, la primera, que no cabe inculpar al ferrocarril del fracaso de la revolución industrial en España (Gómez Mendoza) y, la segunda, que no se puede negar el papel que desempeñó en la modernización de la economía de nuestro país (Anes).

Es verdad que levantar la red ferroviaria española fue, por los propios rasgos fisiográficos del país y por el relativo marasmo de su economía, un empeño de primer orden, que movilizó grandes recursos y tuvo consecuencias duraderas. La absorción de capitales que supuso, su carácter, no se sabe bien si prematuro o tardío (diríase más bien lo primero, pese a la opinión contraria de Rafael Anes), la red radial o arborescente y no reticular, la primacía que apoyada por el Estado se otorgó a los intereses extranjeros, la ausencia de la industria nacional en su construcción, el ancho de vía, etc., son motivos que 
se han aducido para afirmar, explícita o implícitamente, que si las cosas se hubiesen hecho de otro modo entonces sí que el ferrocarril hubiera aportado una contribución sustancial, o incluso decisiva, a la industrialización de España.

Las investigaciones rigurosas que se vienen haciendo, y de las que se hace balance en estos artículos, demuestran bastante convincentemente que no sólo hubiera sido difícil o imposible construir de otra manera el ferrocarril, sino también que la red de caminos de hierro suponía yugular importantes estrangulamientos en el transporte - que tarde o temprano había que vencer-, y que si no dio a la economía entera el tirón que ésta necesitaba fue, una vez más, porque fallaba el conjunto de todos los demás sectores de la economía, con la agricultura a la cabeza.

Quizá las técnicas que intentan aquilatar el «ahorro social» que reportaron a la economía los ferrocarriles sean discutibles y no susciten el entusiasmo unánime de los estudiosos en España ni en otras partes, pero aunque no se acepten esas conclusiones como definitivas es obvio que revisten gran interés los datos que ofrece Gómez Mendoza en un encuadre dentro de su artículo donde explica, brevemente, el método del ahorro social en materia ferroviaria y lo que supuso ese ahorro para varios países.

También hay que señalar el trabajo del mismo autor que, con el título «Transportes y crecimiento económico (1830-1930)», figura en La modernización, con una interesante introducción sobre los efectos hacia atrás y hacia delante (backward y forward linkages) de los nuevos medios de comunicación, así como unos apartados sobre los transportes en España a comienzos del siglo xIx y la política en esa esfera a mediados de centuria. En 1856, Francia disponía de una red caminera ocho veces más extensa que la española, además de $11.000 \mathrm{Km}$. de vías de navegación interior, lo que indica el retraso de nuestro país. Interesante resulta también la referencia a la posibilidad, en teoría, de invertir en capital fijo social (CFS) o en actividades directamente productivas (ADP). El dilema se resolvió en España a favor de la primera opción, con la construcción del ferrocarril, y cabe preguntarse si no hubiera sido mejor lo segundo. Quede aquí expuesta mi opinión de que, al margen de los argumentos teóricos que siempre existen en pro de una u otra postura, la experiencia histórica, con contadas salvedades, parece demostrar que implantar en un país en las etapas iniciales la infraestructura o el CFS resulta una vía más difícil, o al menos más larga, hacia el desarrollo. Sería, por cierto, la que han elegido históricamente los países comunistas.

\section{Banca y sector financiero}

A decir verdad, de los tres trabajos que incluyo bajo este epígrafe - dos de Pedro Tedde, publicados en Papeles («Banca privada y crecimiento econó- 
mico en España, 1874-1913») e ICE («El sector financiero y el fracaso de la Revolución Industrial, 1814-1913»), y uno de Pablo Martín Aceña en La modernización ( Desarrollo y modernización del sistema financiero, 18441935»)-, el primero de Tedde está dedicado en su tercera parte a hablar del sistema fiscal, por lo que pudiera figurar igualmente en el apartado siguiente. Tanto más cuanto que son las únicas páginas de las tres publicaciones aquí reseñadas donde se examinan, aunque sea brevemente, los problemas generales de la Hacienda pública del siglo xIx (pues, como veremos, el único trabajo que habla de las grandes dificultades fiscales de la centuria pasada se refiere sólo a la política tributaria del sexenio liberal). ¿Por qué esta renuencia de los historiadores de la economía a abordar capítulo tan fundamental?

Tedde, en su artículo de Papeles, para explicar el papel que desempeñó el sector financiero en el fracaso de la revolución industrial, ha de referirse, claro es, a la debilidad e insuficiencia del sistema impositivo, constantes durante todo el siglo pasado, pese a las notables mejoras que acarrearon las reformas de Mon-Santillán de 1845 y de Fernández Villaverde de 1899-1900. El remedio fue el recurso al Banco de España y el endeudamiento público, sin que los capitales así allegados se canalizaran casi nunca hacia inversiones productivas. Esta omisión quita toda justificación económica a esos procedimientos, aunque sí hubiera motivaciones políticas de peso, pues se trataba de evitar como fuera la quiebra o el colapso del Estado.

Con ese trasfondo, Tedde responde en el artículo de ICE a la pregunta de si el escaso o nulo papel del Banco de España como banco de bancos fue determinante del fracaso de la revolución industrial. Su respuesta, matizada por sectores y regiones, muestra que más que falta de ahorro había escasez de buenos intermediarios financieros, puesto que cuando existían, como en el caso de la Banca extranjera interesada en obtener fondos nacionales para los ferrocarriles, los conseguían. También es verdad que, entre 1874 y 1900, los intermediarios no sabían, al parecer, qué hacer con los recursos propios y ajenos de que disponían...

Con todo, la Banca fue mejorandr gradualmente, dando un gran paso hacia adelante desde 1900 , aunque hasta 1913 no pudiera decirse que empezaba a ponerse a la altura de la de los países avanzados.

Ese período crítico de 1874-1913 lo estudia con mayor detalle Tedde en su artículo de Papeles, para explicar, entre otras cosas, el desafortunado - por sus negativas consecuencias para Cataluña, y pienso también que para España en su conjunto- declive de la Banca catalana. Las características de la industria textil (con sus escasas necesidades de capital fijo y su fragmentación), la competencia del Banco de España y de las agencias de los grandes bancos madrileños y vizcaínos, podrían explicar hecho tan peculiar en una región que, 
por figurar a la cabeza del desarrollo, ofrecía una capacidad de ahorro lógicamente importante.

Pablo Martín Aceña hace una excelente síntesis del sistema financiero entre 1844 y 1935 . En pocas páginas, se ofrece aquí algo que será muy útil a todos los que enseñamos historia económica de ese período: una exposición resumida pero completa y documentada de una esfera compleja y difícil de captar en su globalidad.

El paso de moneda metálica a fiduciaria y de dinero legal a bancario son jalones fundamentales de la historia financiera, cuyas etapas, con un análisis cuantitativo de la evolución de los activos financieros por sectores, con comparaciones con Europa, las variaciones de oferta monetaria y disponibilidades líquidas, etc., son los principales aspectos tratados en una labor muy meritoria desde el punto de vista investigador y didáctico.

\section{Hacienda pública y sistema fiscal}

Antón Costas Comesaña, en «Política tributaria y desarrollo económico durante el sexenio liberal», Papeles, se pregunta por qué los cambios políticos revolucionarios que trajo la Gloriosa de 1868 arrojaron tan exiguos logros económicos y hacendísticos. ¿Exceso de doctrinarismo? ¿Traición a los principios? ¿Incapacidad de políticos y economistas? Por lo pronto, tal y como ha acontecido siempre sin excepción en la historia de España, la llegada al poder de la izquierda de entonces se produjo dentro de una crisis económica, iniciada ya en 1864 y que, a juicio del autor, consistía en la primera crisis moderna que redoblaba los efectos de una crisis de tipo tradicional.

Había dos estrategias posibles, la visión económica consistente en nivelar gradualmente el presupuesto, tal como querían Figuerola y Echegaray, y la visión fiscal de la nivelación rápida, que preconizaba Ardanaz y que fue la que triunfó, tras una primera fase. El cambio, con la dimisión de Figuerola, se explicaba porque la estrategia gradual obligaba, claro está, a una política de endeudamiento que sólo podía hacerse en condiciones leoninas y porque «la realidad de los hechos tributarios no respondió a las mínimas previsiones recaudatorias ... especialmente en aquellos tributos que, como la contribución industrial, mejor caracterizaban el sentido de la reforma, es decir, captar a través de los rendimientos de la actividad mercantil e industrial lo que ante. riormente se captaba sobre la circulación de los productos».

La inestabilidad política que acompañó a la revolución, la mala gestión y organización tributarias (pese a los esfuerzos desplegados por el propio Figuerola), la kcrisis industrial, crisis monetaria, crisis de los ferrocarriles, crisis financiera, crisis presupuestaria y crisis comercial», visibles desde 1866, amén 
de la crisis de subsistencias de tipo tradicional de 1867-68, ofrecían un panorama muy poco halagüeño para conseguir resultados inmediatos, sobre todo para una política tributaria liberal que se proponía impulsar el desarrollo industrial.

Un buen trabajo, en suma, que cobrará todo su valor cuando se publique la tesis doctoral de que forma parte (Politica Económica y Reforma Liberal, 1868-1874), ya que el artículo deja cabos sueltos y no responde a su título, pues no se habla para nada del desarrollo industrial.

También en Papeles figura un trabajo de Herbert S. Klein sobre las «Ultimas tendencias en el estudio de la Hacienda colonial hispanoamericanam, cuyas conclusiones generales señalan que esa Hacienda era más racional que la de la metrópoli, donde reinaba mucha mayor confusión, al solaparse, por ejemplo, las cajas recaudatorias, cuando en los territorios americanos se adecuaban a los distritos geográficos. (Tal cosa facilita su estudio $y$, por su conducto, el de la economía.) De este trabajo se desprende que la economía colonial fue viva y floreciente, con mucho en común con la de la Europa occidental, pero también con notorias peculiaridades, como, por ejemplo, el que muchas zonas escaparan a la crisis del siglo xvir.

\section{Industria}

En un sucinto pero denso trabajo ( «El fracaso de la Revolución Industrial en España: un modelo cerrado de industrialización») publicado en ICE, Pedro Fraile pone en tela de juicio la hipótesis «a la Nurkse» (papel exclusivo del mercado interno en el desarrollo) que defiende Nadal en El fracaso de la Revolución Industrial. Lo hace no sólo con el argumento -avalado por la teoría y la historia - de que en el desarrollo económico no cabe sólo fijarse en la demanda nacional y prescindir de la demanda externa y de la oferta, sino también con datos comparados sobre producción y renta en la España y la Europa periférica del siglo XIx. Datos, o más bien estimaciones, que indican que España no era un país tan atrasado y que el PNB per cápita era en el siglo pasado entre el 10 y el 40 por 100 más alto que la media de Austria-Hungría, Bulgaria, Finlandia, Grecia, Italia, Portugal, Rumanía, Rusia, Servia y Suecia.

Todo esto, claro está, plantea la cuestión de qué es lo que falló entonces en España, puesto que había una demanda interna que podía hacerse solvente y una demanda exterior potencialmente muy fuerte. La respuesta por la que parece inclinarse Fraile apuntaría más hacia la oferta, y más concretamente, por lo que dice este autor en las últimas líneas de su trabajo, al empresariado. Respuesta que sólo entreabre puertas o esboza soluciones, pero de modo sugerente $y$ en un trabajo de gran altura. 
En realidad, García Delgado, Chastagnaret, Tedde y Tortella habían ya puesto objeciones a la interpretación nadaliana o nurkseriana. Lo recuerda Albert Carreras en su artículo, también en ICE, sobre «Las industrias de bienes de consumo en el siglo XIX». Polémica que hoy tal vez se avive, pero que fue menor que la investigación realizada en el último decenio en la industria ligera de los siglos xIX y primera parte del xx, esfera en la que brilla con luz particular el propio Carreras. Este autor, siguiendo precisamente los consejos de Nadal, ha roto la limitación sectorial y regional del planteamiento que se hace del sector manufacturero en El fracaso de la Revolución Industrial - sólo el algodón, sólo Cataluña - para hacer investigaciones en campos más extensos. Más extensos y más comparativos, puesto que la tesis de Carreras, todavía inédita, versa sobre la producción española e italiana desde mediados del siglo pasado.

Una relación de lo que se está haciendo y con qué fuentes en Cataluña (por Nadal, Carreras y otros) y en otras partes indica, en efecto, que se está avanzando mucho en el conocimiento histórico de todo el sector textil y demás industrias de bienes de consumo. Las conclusiones que avanza Carreras son ya apreciables y las investigaciones en curso prometen mayor cosecha. Reviste interés su hipótesis de que para $1830-1860$ pudiera ser válido el aserto de Nadal de que la insuficiente demanda interna ralentizó el crecimiento de la industria algodonera y que, en cambio, en 1870-1910 fue la rigidez de una oferta amparada en el proteccionismo la que hizo perder pulso al sector.

Aunque queden pendientes todavía, como no podía por menos, las respuestas acerca de las verdaderas causas del éxito y el fracaso de las industrias de bienes de consumo y su papel en el fracaso de la revolución industrial, el material que se va aportando es de primera calidad.

\section{Minería}

«El sector minero» se titula el trabajo de Sebastián Coll Martín que se recoge en $I C E$, y que es el único sobre este sector que figura en las tres publicaciones aquí reseñadas.

El carbón es el primer apartado donde, a la vista de las investigaciones efectuadas en los diez últimos años, entre ellas las del propio Coll, éste concluye que: 1) la desventaja de precio de los carbones españoles se explica sobre todo por las malas condiciones naturales en que se obtiene este mineral en nuestro país; 2) tal desventaja no se compensaba con protección arancelaria, erigida con el argumento de la industria incipiente (lo que da razón a lo que venían diciendo Tortella y otros), y 3 ) que ese carbón más caro no influyó mayormente en el desarrollo. 
Por lo que hace a los minerales metálicos, segundo apartado del artículo, hace Coll un muy interesante «contrafactual», basado en la hipótesis teórica de que las minas hubieran sido explotadas sin capital foráneo. Aquí la conclusión del autor -que, salvo mejor opinión, parece convincente- es que si bien no está demostrado que la inversión extranjera acelerara el crecimiento económico del país, lo que sí cabe afirmar es que tal inversión no fue una mala opción. Las últimas frases del artículo, por cierto, donde se señala eso están mal redactadas o se ha deslizado en ellas una errata, pues parecen afirmar lo contrario de lo que quieren decir.

\section{La economía del siglo XIX en su conjunto}

Gabriel Tortella, en el artículo que abre el número de ICE, levanta bastantes liebres en relación con «El éxito de $E l$ fracaso...; o Jordi Nadal y diez más ante la economía española del XIX».

Además de elogiar como se merece la obra de Nadal, recuerda Tortella la conveniencia o necesidad de abordar otros temas como la población en tanto que factor de producción, el papel del Estado, el comercio exterior y el sector financiero. Nadal soslaya, además, dos cuestiones fundamentales: ¿cuáles fueron las causas del atraso agrícola?; ¿no hubiera podido la industria española buscar en los mercados exteriores una compensación a la exigüedad del mercado nacional?

Insiste Tortella en su conocida posición de que hubiera sido beneficioso un mayor ensamblaje de la economía hispana con el exterior. Recuerda que «el sistema monetario y el aduanero actuaban como poderosos amortiguadores que aislaban la economía, la mantenían anquilosada, e impedían el cambio y el crecimiento». Por último, en dos páginas de lectura muy recomendable hace un rápido inventario de los puntos fundamentales que quedan por despejar en la historia económica del siglo xix. Labor que se está haciendo o que queda pendiente, pero que contribuirá, como dice Tortella con razón, al avance de la teoría del crecimiento económico. Por haberse desarrollado a cámara lenta, España ofrece un campo de estudio privilegiado. La nueva cara de la historia económica no sólo está permitiendo conocer mejor nuestro pasado, sino que puede aportar granos de arena al estudio de problemas fundamentales para el pasado y presente de la economía mundial. ¿Cuál es el papel de la inversión exterior? ¿Cuándo y por qué una agricultura da el gran salto cualitativo hacia adelante? ¿Cómo puede hacerse una reforma agraria eficaz que no arruine a los campesinos pobres? ¿Cómo cabe asignar un capital escaso de la mejor manera? ¿Cómo un país con buenos recursos naturales - como era el caso de los minerales metálicos en la España del xIx- puede sacarles el mejor pro- 
vecho? ¿Cómo allegar capitales extranjeros sin endeudarse demasiado o depender en exceso del extranjero? ¿Hay que proteger a la industria nacional? ¿Cuánto y hasta cuándo? Las preguntas que suscita Tortella no son baladíes, ni intentar dar respuesta es tarea mostrenca.

José Luis García Delgado escribe, también en ICE, sobre «El fracaso, a diez años vista»: Recuerda que la obra de Nadal constituye un estimulante punto de partida, pero también es culminación de muchos trabajos anteriores de otros autores, a los que García Delgado rinde justicia citándolos.

Según este autor, entre las virtudes de El fracaso figurarían la base documental y el alejamiento de toda interpretación especulativa. Nada sustituye, bueno es recordarlo ahora y siempre, a la investigación. Señalar el peso del endeudamiento del Estado, el incumplimiento por el Banco de España de su papel como vector de la política monetaria, la competencia que hizo el Estado a quienes querían obtener capitales, las compensaciones directas e indirectas que el endeudamiento obligó a facilitar a la inversión extranjera, son, entre otros, los logros más notables, a juicio de García Delgado, de esa obra.

Aspectos más discutibles serían el tomar como referencia el modelo inglés y no buscar contrastes en países de la periferia o del área mediterránea (con sus modelos de crecimiento lento más semejantes al español), la visión nacionalista y negativa del papel del capital exterior o la discriminación a favor del empresariado textil, cuyos problemas los achaca Nadal a la insuficiente demanda y no, en cambio, a los costes, como hace con el carbón y la siderurgia.

Con su peculiar estilo, sus muchos conocimientos y su fuerte personalidad, Jordi Nadal escribe en Papeles un artículo que titula «El fracaso de la Revolución Industrial. Un balance historiográficom, y que es más bien una mezcla de tesis anteriores, de nuevos e interesantes matices en unos cuantos puntos y de una referencia escasa a la historiografía sobre el tema (que, como demuestran, entre otras, las publicaciones aquí comentadas, es muy abundante).

Recuerda Nadal de entrada que España en materia de industrialización no ha sido un late joiner, sino un first comer fracasado, y que tal fracaso tiende a veces a explicarse por factores sólo endógenos (Tortella) o únicamente exógenos ( $\mathrm{J}$. Acosta), lo que merece una dura reprobación del historiador catalán. Justa en el segundo caso, no lo es en el primero, pues ni Tortella busca explicaciones unilaterales (lo que dice es que no hay que echar la culpa del fracaso a los factores externos, que no es lo mismo) ni la frase de Nadal de que «esta clase de juicios, tan rotundos, se sustenta más en una pobreza de conocimientos alarmante que en un nivel de investigación avanzado puede aplicarse en absoluto a Tortella. Quizá todo sea una defectuosa redacción, pero lo que se nos dice resulta desafortunado.

$\mathrm{Al}$ pasar revista a los principales sectores o capítulos, Nadal divide el acontecer económico en factores de producción, factores de consumo, papel del 
Estado y sectores industriales. Tal desglose es discutible, pues le lleva a incluir a la agricultura entre los factores de producción y a dedicar, en cambio, un apartado específico a la industria. Bajo el primer epígrafe habla muy rápidamente de agricultura, recursos mineros, fuentes de energía, capitales y población. (En el penúltimo de estos apartados, para explicar el subdesarrollo bancario catalán desde finales del siglo xIx, recurre nuestro autor no sólo a los rasgos propios de la industria algodonera, lo que, como hemos visto, puede ser convincente, sino también a la «falta de capacidad adquisitiva del consumidor peninsular", lo que sorprende, pues tal cosa, sin duda cierta, no impidió la expansión de la Banca vasca y madrileña.)

Entre los factores de consumo, se aborda en una curiosa yuxtaposición la evolución demográfica, donde sigue insistiendo nuestro autor en la singularidad de la población española -que yo no creo que exista-, la pérdida de las colonias, la formación del mercado interior y el ferrocarril.

En el papel del Estado, tal vez por las prisas de tan apretada síntesis, despacha Nadal en tres párrafos nada menos que la existencia de una supuesta vía española de transición del feudalismo al capitalismo, con algunas afirmaciones que parecen tomadas de las tesis de Fontana que examinamos más adelante. Menos polémicos resultan los apartados siguientes de este epígrafe sobre el papel subordinado de la burguesía industrial, el endoso de la carga fiscal (aunque no está claro a quién se endosa) o la deuda pública.

En el último epígrafe sobre los sectores industriales, donde se desenvuelve como pez en el agua, Nadal nos recuerda la utilidad de las fuentes fiscales, se corrige a sí mismo al decir que en industria no hay que hablar sólo de algodón y siderurgia, sostiene -en contraposición flagrante con las conclusiones de Pedro Fraile que ya hemos comentado- que habida cuenta del nivel de rentas de la población española sorprende la capacidad de los algodoneros catalanes para consolidar su negocio y extender el mercado, se defiende con habilidad de las tesis contrarias a su posición de que la franquicia aduanera en la construcción del ferrocarril influyó negativamente en la siderurgia y acaba con unas breves palabras sobre la industria química.

En conclusión, un trabajo sugeștivo, polémico, como todos los de Nadal, y que tienen siempre el gran mérito de estar basados en una sólida documentación y en muchas horas de investigación, con esa mezcla tan característica del gran historiador catalán que le lleva a darnos el dato pormenorizado ( $y$ perfectamente documentado) en un párrafo y a esbozar en el siguiente, con cierta rotundidad, una teoría de la transición al capitalismo o de la industrialización.

En el siglo xIx, como en cualquier otra época, además de economía hay política, sociedad y muchas cosas más. A economistas e historiadores de la economía se nos olvida esto a veces, y por eso siempre es una sorpresa y -para muchos, entre los que me cuento- una satisfacción tropezar con Josep 
Fontana y sus intentos de historia global, de una historia económica que tenga en cuenta no sólo lo estrictamente económico, sino que se «repolitice», como él mismo dice. «Incluso si nos limitamos al terreno estricto del cambio económico - dice Fontana-, está claro que cualquier explicación medianamente satisfactoria de la crisis [del Antiguo Régimen] ha de tomar en cuenta la quiebra fiscal de la monarquía absoluta, la ruptura de los equilibrios económicos internacionales que significó la pérdida de las colonias continentales americanas, las diversas soluciones postuladas para remediar tal situación... y las actuaciones políticas que derivaron de estas propuestas."

Como sobre lo que escribe este autor (en Papeles) es sobre «La crisis del Antiguo Régimen en España», lo que nos viene a decir es que las relaciones sociales de producción, que se habían mantenido bastante estables - pero no inmóviles- durante casi siglos, se modificaron por entero en menos de treinta años. ¿Cómo fue posible tanto cambio? ¿Por qué no tuvo más efectos en
el crecimiento económico?

La primera pregunta parece responderla Fontana basándose en la idea de que la nobleza se alió con la burguesía contra los campesinos para hacer la reforma liberal, con el consiguiente perjuicio para estos últimos a corto plazo y también a la larga, al no promover aquellas modificaciones una revolución industrial completa. La consolidación de la propiedad feudal en propiedad burguesa lo expresa muy gráficamente Fontana cuando dice que en el siglo xIx sino de los campesinos.

No hubo crecimiento económico porque la vía del cambio agrícola era la adecuada para asentar el beneficio capitalista, pero no para propiciar el crecimiento del producto agrario. Las nuevas reglas del juego favorecían a los grandes propietarios $\mathrm{y}$, por la propia dinámica que entrañó, con el aumento de la producción de cereales, el cultivo de tierras marginales, la desaparición de las relaciones entre ganadería y agricultura propias de la agricultura tradicional, no sólo expulsó de la tierra, y hasta del país, a grandes masas de campesinos arruinados, sino que dejó al sector primario indefenso para afrontar los cambios sobrevenidos en las relaciones económicas internacionales.

No cabe duda de que estas hipótesis son sugerentes y atractivas, sobre todo al estar expuestas con rigor y al amparo de una base documental y bibliográfica que resultaría prodigiosa si no nos tuviera Fontana ya acostumbrados a ello. Las reflexiones, dudas o preguntas que suscita todo esto son demasiado numerosas para exponerlas aquí. Sólo indicaré dos. ¿Cómo hubo entonces tanta oposición política a la reforma, y no sólo por parte de campesinos? Admitiendo que los intereses de los grupos sociales son siempre a corto plazo, ¿por qué la reforma liberal en tantos otros países surtió efectos más beneficiosos que en España, para los propietarios y también, a la postre, para los campesinos? 
A esto segundo, Fontana respondería probablemente que fue la relación de fuerzas entre las diferentes clases lo que obligó a hacer las cosas de otro modo en distintas latitudes. Pero está claro que esa conjunción de fuerzas sociales, históricas y económicas, tan difíciles de precisar y, sobre todo, de cuantificar, tuvieron una resultante negativa en unos casos y positiva en otros, y a España nos correspondió, para nuestra desgracia, figurar entre los primeros.

Acostumbrados como estábamos a ver en la resistencia de las clases hegemónicas del Antiguo Régimen uno de los motivos del fracaso de la revolución industrial, tendríamos que revisar ahora nuestras ideas para aceptar que aquellos nobles y propietarios se pasaron al liberalismo para así defender mejor sus intereses. Pero como las consecuencias fueron igualmente nocivas para el país en su conjunto, me pregunto si al fin y al cabo no queda todo igual, pues fueron unos grupos sociales miopes y egoístas los que, fieles o no a sus orígenes de clase, impidieron que la burguesía desempeñara en nuestra historia el papel revolucionario de que habla el Marx del Manifiesto.

En la introducción a La modernización hace Nicolás Sánchez-Albornoz un repaso al tema a que está dedicado el libro: la economía española entre 1830 y 1930, período en el que, «a la postre, los cambios ocurridos incidieron sobre la vida de los habitantes del país más que la adquisición de un vasto y rico imperio ultramarino en el siglo xvI».

España, situada en la periferia inmediata de un «centro» primeramente industrializado, se benefició, sin duda, de su situación relativamente privilegiada. Absorbió tecnología, recibió capitales y comerció con el exterior, aunque las ventajas de los dos últimos aspectos hayan sido y sigan siendo discutidas.

Pero el crecimiento y la modernización fueron equívocos, como ambigua era la posición de España, con la paradoja, además, de que, junto con Portugal, iniciara nuestro país la era de los descubrimientos que sentó las bases del esplendor europeo y del consiguiente desarrollo económico, en el que la Península Ibérica se quedó claramente a la zaga.

Crecimiento desequilibrado, además, el español, con dos etapas: una primera, hasta fin de siglo, «de recalentamiento, de cambios irregulares e insuficientes, pero preparatorios»; la segunda, en el primer tercio del siglo $\mathrm{xx}$, «de transformaciones ya significativas, por más que sus marcas queden aún por detrás - con un retraso algunas de casi medio siglo- con respecto de las de otros países europeos». La modernización llega tarde, dice Sánchez-Albornoz, y en 1930, donde el libro sobre La modernización deja el tema, no había concluido. 


\section{A P ENDICE \\ Artículos citados, clasificados por materias y en el orden en que figuran reseñados}

Abreviaturas: Papeles $=$ Papeles de Economía Española, núm. 20, Fundación Fondo para la Investigación Económica y Social, de la Confederación Española de Cajas de Ahorro, Madrid, sin fecha (publicado en 1985).

La modernización $=$ La modernización económica de España 1830-1930, compilación de Nicolás Sánchez-Albornoz, Alianza Universidad, Madrid, 1985.

ICE = Información Comercial Española, núm. 623, Ministerio de Economia y Hacienda, Madrid, julio 1985.

\section{Agricultura}

Gabriel Tortella: «La agricultura en la economía de la España contemporánea: 1830. 1930w, Papeles.

- «Producción y productividad agraria, 1830-1930», La modernización.

Gonzalo ANEs: «El sector agrario en la España moderna*, Papeles.

Francisco Simón Segura: «La desamortización española del siglo xix*, Papeles.

Germán RuEda: aLa desamortización de Mendizábal y Espartero», ICE.

Javier M. Donézar: «Los bienes de los pueblos y la desamortización», ICE.

\section{Población}

Nicolás SÁnch ez-Albornoz: «Población y economía en Iberoamérica en los siglos xix y XX*, Papeles.

Vicente Pérez Moreda: «Evolución de la población española desde finales del Antiguo Régimen», Papeles.

- "La modernización demográfica, 1830-1930. Sus limitaciones y cronología», La modernización.

- «La población española del siglo xix y primer tercio del siglo $x x \star, I C E$.

Francisco Bustelo: «La población española del siglo XIX: un crecimiento preindustrial», ICE.

\section{Comercio exterior}

Leandro Prados de la Escosura: «La evolución del comercio exterior, 1790-1929», Pa. peles.

- *El comercio exterior y la economía española durante el siglo XIX*, La modernización.

\section{Ferrocarriles}

Antonio Gómez Mendoza: «Los efectos del ferrocarril sobre la economía española, 1855 1913*, Papeles.

- "Transportes y crecimiento económico, 1830-1930», La modernización.

Rafael ANEs: «El ferrocarril en la economía española», ICE.

\section{Banca y sector financtero}

Pedro Tedde: «Banca privada y crecimiento económico en España, 1874-1913», Papeles. - El sector financiero y el fracaso de la Revolución Industrial, 1814-1913\%, ICE.

Pablo Martín ACEÑA: «Desarrollo y modernización del sistema financiero, 1844-1935*, La modernización. 
Hacienda pública y sistema fiscal

Antón Costas Comesaña: «Política tributaria y desarrollo económico industrial durante el sexenio liberaln, Papeles.

Herbert S. Klein: «Ultimas tendencias en el estudio de la Hacienda colonial hispanoamericanax, Papeles.

\section{Industria}

Pedro Fraile: «El fracaso de la Revolución Industrial en España: un modelo cerrado de industrialización», $I C E$.

Albert Carreras: «Industrias de bienes de consumo», ICE.

\section{Minería}

Sebastián Coll Martín: «El sector minero», ICE.

\section{Sobre el siglo XIX en general}

Gabriel Tortella: "El éxito de El fracaso...; o Jordi Nadal y diez más ante la economía española del $\mathrm{xIX»}, I C E$.

José Luis García Delgado: "Sobre El fracaso de la Revolución Industrial en España, diez años después», ICE.

Jordi NADAL: «El fracaso de la Revolución Industrial en España. Un balance historiográficom, Papeles.

Josep Fontana: aLa crisis del Antiguo Régimen en Españan, Papeles.

Nicolás SÁNCHEZ-AlBORNOZ: «La modernización económica», La modernización. 